\title{
Short-Term Clinical and Return-to-Work Outcomes After Arthroscopic Suprapectoral Onlay Biceps Tenodesis With a Single Suture Anchor
}

\author{
Brandon C. Cabarcas, M.D., Alexander Beletsky, M.D., Joseph Liu, M.D., \\ Anirudh K. Gowd, M.D., Brandon J. Manderle, M.D., Matthew Cohn, M.D., and \\ Nikhil N. Verma, M.D.
}

\begin{abstract}
Purpose: To describe short-term outcomes of arthroscopic suprapectoral onlay biceps tenodesis using a single allsuture anchor with respect to validated outcome measures, return to work, objective strength and motion data, and biceps-specific testing. Methods: This study describes a consecutive series of patients undergoing arthroscopic suprapectoral onlay biceps tenodesis performed by a single surgeon from January to December 2017. Patients were evaluated preoperatively and postoperatively with the American Shoulder and Elbow Surgeons questionnaire, visual analog scale, Single Assessment Numeric Evaluation, Veterans RAND 12-Item Health Survey, and 12-Item Short Form survey, and return-to-work survey. Postoperative strength, range of motion, and biceps-specific testing was also performed. Results: This study included 50 patients (26 men and 24 women), with an average age ( \pm standard deviation) of $50.1 \pm 10.9$ years and average final follow-up of $21.3 \pm 8.5$ months. Among employed patients, $32(71.1 \%)$ returned to work at an average of $4.6 \pm 2.3$ months. Light-duty workers returned to work at a significantly greater rate $(85.7 \%$ vs $33.3 \%, P=.016)$ and in less time $(2.6 \pm 2.0$ months vs $6.8 \pm 4.2$ months $)$ than heavy-duty workers. No differences were found between operative and nonoperative sides in the biceps apex distance $(P=.636)$ or range of motion in elbow flexion and extension $(P>.9$ for both), supination $(P=.192)$, or pronation $(P=.343)$ postoperatively. Strength in elbow flexion $(P=.002)$, as well as shoulder forward elevation $(P<.001)$ and external rotation $(P<.001)$, increased postoperatively. Significant patient-reported improvements were noted in the American Shoulder and Elbow Surgeons score, visual analog scale pain score, Single Assessment Numeric Evaluation score, Constant-Murley score, and Veterans RAND 12-Item Health Survey and 12-Item Short Form physical component scores $(P \leq .001$ for all $)$. A postoperative Popeye deformity developed in 5 patients (10\%). Conclusions: Arthroscopic suprapectoral onlay biceps tenodesis with a single all-suture anchor can provide overall excellent clinical outcomes regarding strength, motion, and validated patient-reported outcome questionnaires. Return to occupational activities may be less predictable and more prolonged for heavy laborers. A small number of patients may experience cosmetic deformity postoperatively. Level of Evidence: Level IV, therapeutic case series.
\end{abstract}

\footnotetext{
From the University of South Florida Morsani College of Medicine, Tampa, Florida, U.S.A. (B.C.C.); Division of Sport Medicine, Midwest Orthopaedics at Rush, Chicago, Illinois, U.S.A. (A.B., B.J.M., M.C., N.N.V.); Department of Orthopaedic Surgery, Loma Linda University Medical Center, Loma Linda, California, U.S.A. (J.L.); and Wake Forest University, Winston-Salem, North Carolina, U.S.A. (A.K.G.).

The authors report the following potential conflicts of interest or sources of funding: J.L. is a paid presenter or speaker for Smith $\theta$ Nephew, outside the submitted work. A.K.G. is on the editorial or governing board of BMC Musculoskeletal Disorders. N.N.V. receives research support from Arthrex, Breg, Ossur, Smith $\theta$ Nephew, and Wright Medical Technology; receives publishing royalties and financial or material support from Arthroscopy and Vindico Medical-Orthopedics Hyperguide; owns stock or stock options in Cymedica, Minivasive, and Omeros; is a paid consultant for Minivasive and Orthospace; and receives intellectual property royalties from Smith $\theta$ Nephew,
}

outside the submitted work. In addition, N.N.V. is a board or committee member of American Orthopaedic Society for Sports Medicine, American Shoulder and Elbow Surgeons, and Arthroscopy Association of North America and is on the editorial or governing board of Knee and SLACK. Full ICMJE author disclosure forms are available for this article online, as supplementary material.

Received November 2, 2020; accepted March 15, 2021.

Address correspondence to Brandon C. Cabarcas, M.D., 5 Tampa General Cir, Ste 710, Tampa, FL 33606, U.S.A. E-mail: bcabarcas44@gmail.com

(C) 2021 THE AUTHORS. Published by Elsevier Inc. on behalf of the Arthroscopy Association of North America. This is an open access article under the CC BY-NC-ND license (http://creativecommons.org/licenses/by-nc-nd/4.0/). 2666-061X/201809

https://doi.org/10.1016/j.asmr.2021.03.012 
$\mathbf{T}$ Tears and tenosynovitis of the long head of the biceps tendon (LHBT) are quite common and can be a source of significant shoulder pain and disability, often accompanying rotator cuff injuries. ${ }^{1-2}$ Intraarticular pathology of the LHBT is commonly treated with tenotomy or tenodesis, with the latter often being preferred in younger patients, athletes, and individuals concerned with avoiding unsatisfactory cosmesis. ${ }^{3-5}$ Historically, biceps tenodesis has typically been performed through an open incision. However, arthroscopic tenodesis has become increasingly common, with previous investigations reporting increasing rates of arthroscopic versus open tenodesis performed over the past 10 to 15 years. ${ }^{5,6}$

The arthroscopic variant of this procedure can be executed using a variety of implants, including suture anchors or interference screws. Open and arthroscopic techniques, with a range of fixation instruments, have been compared biomechanically, with similar findings in repair strength, ultimate load to failure, and stiffness at time $0 .^{7-11}$ Early clinical investigations have shown comparable overall postoperative outcomes when analyzing arthroscopic versus open techniques as well. ${ }^{4,5}$ However, the available literature is limited regarding return to work (RTW) or other necessary functional activities after arthroscopic biceps tenodesis. Prior studies have described rates of return to sport of $69.9 \%$ and $78.3 \%$ after open and arthroscopic tenodesis procedures, respectively. ${ }^{12}$ Investigations reporting rates of RTW are similarly scarce, with those published reporting nearly an $80 \%$ RTW rate before 6 months in a mixed cohort of patients undergoing arthroscopic or open biceps tenodesis. ${ }^{13}$

The purpose of this study was to describe short-term outcomes of arthroscopic suprapectoral onlay biceps tenodesis using a single all-suture anchor with respect to validated outcome measures, RTW, objective strength and motion data, and biceps-specific testing. We hypothesized that postoperative patient outcome scores, strength, and range of motion (ROM) would all improve significantly compared with preoperative levels and that patients would return to occupational activities at high rates.

\section{Methods}

\section{Study Design and Data Collection}

Appropriate review was performed and approval was granted by the study site's institutional review board prior to commencement of this investigation. A retrospective query of a prospectively collected clinical institutional database was performed to identify eligible study subjects and relevant clinical outcome metrics. All consecutive patients who underwent an arthroscopic shoulder procedure that included an arthroscopic suprapectoral onlay biceps tenodesis using a single all-suture anchor performed by the senior author (N.N.V.) between January and December 2017 were eligible for inclusion. The indications for surgery were as follows: anterior shoulder pain, LHBT tendinopathy or tear, partial- or full-thickness rotator cuff tear with associated LHBT tendinopathy, SLAP tear, bicipital instability, and LHBT tendinitis refractory to conservative management. Both primary and revision cases were included. Prior to surgery, patients were asked to complete a standardized set of validated patientreported outcome measure (PROM) questionnaires given to all patients undergoing this type of procedure at the investigating institution. In addition, patient demographic characteristics were compiled, including age at the time of surgery, sex, body mass index (BMI), handedness, side of surgery, Workers' Compensation status, work status and level of duty, and select comorbidities (smoking status, hypertension, diabetes, hypercholesterolemia, thyroid disease, or psychiatric condition). Surgical details and concomitant procedures were also recorded.

\section{Clinical Outcomes}

Postoperatively, patients were administered validated outcome questionnaires at 6 months and 1 year after surgery, as is the standard of practice at the investigating institution. The questionnaires were administered via a Web-based data collection service (OBERD: Outcomes Based Electronic Research Database; Universal Research Solutions, Columbia, MO). Shoulderspecific metrics included the American Shoulder and Elbow Surgeons (ASES) score, subjective ConstantMurley score (CMS), and Single Assessment Numeric Evaluation (SANE) score. ${ }^{14-17}$ Other general physical and mental health information was collected via a visual analog scale (VAS), the Veterans RAND 12-Item Health Survey (VR-12), and the 12-item Short Form (SF-12) survey. ${ }^{18-20}$ Both VR-12 and SF-12 results were reported with respect to the individual mental component score (MCS) and physical component score (PCS). Once patients reached a minimum of 12 months beyond the date of surgery, they were contacted via telephone and/or e-mail and administered a subset of the patient-reported outcome questionnaires (ASES and SANE) to decrease potential survey burden. A total of 3 phone call attempts were made and 3 e-mail messages were sent to all included patients. If no response was given at that point, these patients were considered lost to follow-up.

Patients were seen for standard clinical follow-up visits at $1,3,6$, and 12 months postoperatively by the senior author, a board-certified, fellowship-trained orthopaedic sports medicine surgeon. At the 6-month visit, an assessment of active and passive shoulder ROM (flexion, abduction, external rotation, and external rotation with $90^{\circ}$ of abduction) and elbow 
ROM (flexion, extension, pronation, and supination) was performed by a clinical member of the research team under supervision and confirmed by the senior author (B.C.C., A.K.G., B.J.M.). Strength testing was also completed in the same manner for elbow flexion and shoulder forward elevation and external rotation for all patients with a dynamometer. In addition, the findings of provocative maneuvers, including the O'Brien test, Speed test, and Yergason test, as well as bicipital groove tenderness, were recorded in a similar fashion. Cosmetic appearance was evaluated by both the patient and operating surgeon (N.N.V.), with assessment for presence of a Popeye deformity, as well as a quantitative measurement of the biceps apex distance. ${ }^{21}$ Given the lack of noninvasive options for direct visualization and postoperative evaluation of the integrity of a tenodesis, the presence of a Popeye deformity was used to approximate clinical failure of the procedure and defined as significant asymmetry, identified by the patient as abnormal. Patients were also asked a standardized set of questions with respect to RTW status and level of duty. Occupational status was stratified on the basis of intensity of work as defined by the U.S. Department of Labor (light, moderate, and heavy duty; Appendix Table 1, available at www. arthroscopyjournal.org). ${ }^{22}$

\section{Surgical Technique}

The preferred patient position for this surgical technique was the beach-chair position with the operative arm held in $45^{\circ}$ of flexion and $30^{\circ}$ of abduction and with slight external rotation to help ensure an appropriate length-tension relation of the LHBT. ${ }^{23}$ Biceps tenodesis was typically performed as the final step if concomitant procedures (e.g., rotator cuff repair) were performed. However, the order of operations was ultimately determined by surgeon preference. An arthroscopic approach with 4 portals (anterior, accessory anterolateral, posterior, and lateral) was consistently used in each surgical case.

Diagnostic arthroscopy was performed initially to assess the humeral head, glenoid fossa, and ligamentous structures, followed by arthroscopic transection of the LHBT. After transection, a lateral viewing portal was used to identify the remaining LHBT in the bicipital groove. The LHBT was palpated within the groove and tensioned with a probe to confirm correct anatomic position. Through an anterior working portal, a radiofrequency ablation device was used to free the LHBT from the intertubercular groove. After release from the groove was confirmed, an arthroscopic grasper was used from the posterior portal to grab the LHBT and provide anterior tension while radiofrequency ablation was used to complete preparation of the tenodesis site within the groove. Through the accessory anterolateral portal, a single-loaded all-suture anchor (2.6-mm single-loaded FiberTak suture anchor; Arthrex, Naples, FL) was placed at the level of the distal aspect of the bicipital groove while anterior tension was maintained with the arthroscopic grasper, above the pectoralis insertion, after release of the transverse humeral ligament. ${ }^{23}$ Tension was then applied to the FiberWire sutures (Arthrex) to verify appropriate strength and confirm correct anchor deployment. The arthroscopic grasper was used through the anterolateral portal to mobilize a free suture medially across the LHBT and create a loop. By use of the grasper, the same free suture end was grasped on the lateral side and passed through the suture loop (Fig 1). An arthroscopic penetrator grasper was then used to pierce the LHBT and grab the free end of the same suture. The 2 suture ends were passed outside of the shoulder through the anterior portal and tied using an arthroscopic knot pusher in an alternating-post manner. The remaining LHBT tissue proximal to the point of fixation was excised with the radiofrequency ablation device and removed from the posterior portal.

After surgery, all patients underwent standardized progressive rehabilitation protocols depending on the respective procedures performed. These typically included brief periods of immobilization or restricted passive ROM exercises in the immediate postoperative period, followed by slow progression to active ROM and strengthening exercises at approximately 6 weeks.

\section{Statistical Analysis}

Statistical analyses were executed with StataIC 15 software (StataCorp, College Station, TX). Descriptive statistics were used to summarize patient demographic characteristics. Univariate analysis was performed with the $\chi^{2}$ test for categorical variables and Student 2-sample paired $t$ test for continuous variables. The Fisher exact test was used when appropriate. With respect to clinically significant outcomes, threshold values for the minimal clinically important difference (MCID) were calculated for each included PROM with a distribution-based methodology using the standard error of the mean (SEM) measurement, as previously described in the literature. $^{24,25}$ In this distribution-based approach, the SEM is calculated for each PROM and used to define the MCID threshold value, given that MCID values are usually 1 SEM or one-half of the standard deviation of the mean. ${ }^{24,25}$ A stepwise multivariate logistic regression was used to examine the impact of demographic and preoperative variables on clinical outcomes, as well as MCID achievement. All independent variables with $P<.15$ were included in the subsequent multivariate analyses using a multivariate binary logistic regression model. Statistically significant correlations were identified with $P<.05$. 


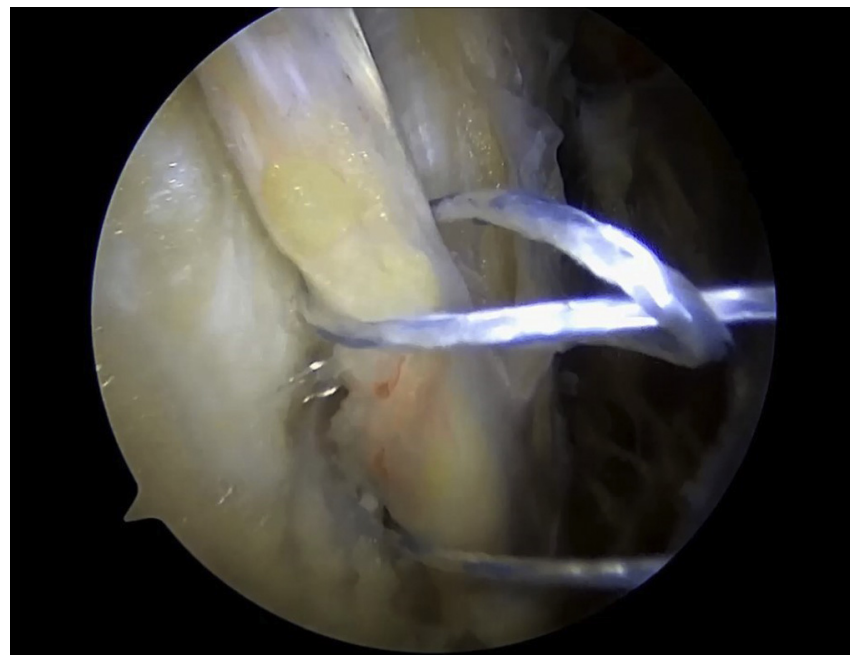

Fig 1. Biceps tenodesis lasso-loop suture anchor configuration in a right shoulder, viewed through a lateral portal, with the patient in the beach-chair position. Onlay biceps tenodesis is performed using a single suture anchor with a loop-lasso configuration.

\section{Results}

\section{Patient Demographic Characteristics}

Of 57 patients potentially eligible for inclusion, 50 $(87.7 \%)$ completed the evaluation at final follow-up (26 men and 24 women) (Table 1). There were 7 patients who did not complete the follow-up physical evaluation and were subsequently excluded from our analysis. The average age was $50.14 \pm 10.93$ years, and the mean final follow-up time was $21.3 \pm 8.5$ months. The average BMI was $30.51 \pm 6.16$. The most common comorbidity within this cohort was hypertension $(\mathrm{n}=$ $11,22 \%)$, whereas the least commonly listed comorbidity was thyroid disease $(\mathrm{n}=2,4 \%)$. Of the 50 patients examined, $30(60 \%)$ were classified as having Workers' Compensation claims. A total of 30 patients $(60 \%)$ underwent rotator cuff repair, 25 of whom $(50 \%)$ received concomitant subacromial decompression (SAD). In contrast, 20 patients $(40 \%)$ underwent procedures that did not involve direct repair of the rotator cuff tendons. There were 12 distal clavicle excisions $(24 \%), 10$ rotator cuff debridements $(20 \%), 2$ lyses of adhesions (4\%), 1 labral repair $(2 \%), 1$ acromioclavicular joint resection (2\%), 1 acromioclavicular joint reconstruction $(2 \%)$, and 1 superior capsular reconstruction $(2 \%)$. Revision procedures were performed in 4 cases $(8 \%)$, which included 1 isolated rotator cuff repair, 1 rotator cuff repair with concomitant SAD, 1 isolated SAD, and I SAD with concomitant distal clavicle excision.

\section{Functional and Patient-Reported Outcomes}

At 6 months postoperatively, significant mean improvements in postoperative shoulder ROM were observed for forward elevation $\left(31.6^{\circ} \pm 43.7^{\circ}, P<.001\right)$, abduction $\left(37.7^{\circ} \pm 32.1^{\circ}, P<.001\right)$, external rotation at $90^{\circ}\left(2.6^{\circ} \pm 3.0^{\circ}, P<.001\right)$, and external rotation with the arm at the side $\left(95.2^{\circ} \pm 9.3^{\circ}, P=.001\right)$ within the study cohort (Table 2). No significant differences in mean postoperative elbow flexion $\left(0.1^{\circ} \pm 7.1^{\circ}, P>.9\right)$, elbow extension $\left(0.1^{\circ} \pm 3.8^{\circ}, P>.9\right)$, supination $\left(2.2^{\circ} \pm 7.7^{\circ}\right.$, $P=.192)$, or pronation $\left(2.7^{\circ} \pm 8.3^{\circ}, P=.343\right)$ ROM were noted between the operated and contralateral elbows among study subjects. The mean postoperative biceps apex distance did not differ significantly between the operated and contralateral extremities $(9.5 \pm 2.2 \mathrm{~cm}$ vs $9.3 \pm 2.2 \mathrm{~cm}$ [range, $6.4-16.9 \mathrm{~cm}$ vs $6.2-16.4 \mathrm{~cm}$ ]; $P=$ .636) within our population. Postoperative strength testing revealed significant mean improvements in shoulder external rotation at the side $(6.1 \pm 5.7 \mathrm{lb}, P<$ $.001)$, forward elevation $(6.4 \pm 5.9 \mathrm{lb}, P<.001)$, and elbow flexion $(6.8 \pm 9.3 \mathrm{lb}, P=.002)$ (Fig 2). There was no significant difference in postoperative elbow flexion strength comparing the operated and contralateral sides $(21.3 \pm 8.6 \mathrm{lb}$ vs $23.1 \pm 10.1 \mathrm{lb}, P=.336)$.

Significant improvements in average PROM scores were observed for the ASES score $(28.8 \pm$ 23.2, $P<.001)$, CMS $(24.6 \pm 14.0, P<.001)$, SANE score $(38.9 \pm 32.1, P<.001)$, VAS score $(-3.0 \pm 3.0$, $P<.001)$, SF-12 PCS $(6.6 \pm 9.3, P=.001)$, and VR-12 PCS $(7.0 \pm 9.4, P<.001)$ at 6 months postoperatively (Table 3 ). These average improvements were all beyond the PROM MCID threshold values. No significant improvements were seen in the SF-12 MCS $(0.9 \pm 9.9, P=.915)$ or VR-12 MCS (1.6 \pm $8.9, P=.417)$ on average. Considering each PROM at 6 months, the MCID threshold was met by 31 patients for the ASES score, 18 patients for the CMS, 27

Table 1. Patient Demographic Characteristics

\begin{tabular}{ll}
\hline \multicolumn{1}{c}{ Characteristic } & \multicolumn{1}{c}{ Data } \\
\hline Age, yr & $50.14 \pm 10.93$ \\
BMI & $30.51 \pm 6.16$ \\
Male/female patients & $26 / 24$ \\
Current/past smoker & $11 / 16$ \\
Hypertension & 11 \\
Psychiatric comorbidity & 2 \\
Diabetes mellitus & 4 \\
Hypercholesterolemia & 6 \\
Thyroid comorbidity & 2 \\
Right/left handed & $47 / 3$ \\
Dominant-side surgery & 27 \\
WC & 30 \\
RCR with SAD & 25 \\
Isolated RCR & 5 \\
No RC involvement & 20 \\
Revision surgery & 4
\end{tabular}

NOTE. Data are presented as mean \pm standard deviation or number of patients.

BMI, body mass index; RC, rotator cuff; RCR, rotator cuff repair; $\mathrm{SAD}$, subacromial decompression; WC, Workers' Compensation. 
Table 2. Average Improvements in Postoperative Shoulder Strength and ROM

\begin{tabular}{lcc}
\hline \multicolumn{1}{c}{ Parameter } & Improvement & $P$ Value \\
\hline ROM, & $31.56 \pm 43.71$ & $<.001^{*}$ \\
FE & $5.21 \pm 9.32$ & $.001^{*}$ \\
ER with arm at side & $2.64 \pm 3.04$ & $<.001^{*}$ \\
ER 90 & $37.69 \pm 32.11$ & $<.001^{*}$ \\
ABD & $0.17 \pm 9.88$ & .915 \\
IR 90 & & \\
Strength, lb & $6.4 \pm 5.9$ & $<.001^{*}$ \\
FE & $6.1 \pm 5.7$ & $<.001^{*}$ \\
ER with arm at side & $6.8 \pm 9.3$ & $.002^{*}$ \\
Elbow flexion &
\end{tabular}

NOTE. Data are presented as mean \pm standard deviation.

$\mathrm{ABD}$, abduction; ER, external rotation; ER $90^{\circ}$, external rotation with arm abducted to $90^{\circ}$; $\mathrm{FE}$, forward elevation; IR $90^{\circ}$, internal rotation with arm abducted to $90^{\circ}$; ROM, range of motion.

*Statistically significant improvement $(P<.05)$.

patients for the SANE score, 27 patients for the VAS score, 22 patients for the SF-12 PCS, 12 patients for the SF-12 MCS, 22 patients for the VR-12 PCS, and 16 patients for the VR-12 MCS. The mean ASES score $(69.2 \pm 19.2, P<.001)$ and SANE score $(73.0 \pm 22.9$, $P<.001)$ at final follow-up postoperatively were significantly improved compared with preoperative levels. At final follow-up, 31 patients met the MCID threshold for the ASES score and 35 patients, for the SANE score. The magnitude of improvement from 6 months to final follow-up was not statistically significant for either the ASES score $(3.2 \pm 17.0, P=.117)$ or SANE score $(5.1 \pm 20.1, P=.132)$.

\section{RTW and Examination of Clinical Failures}

A total of 44 patients $(88 \%)$ endorsed holding an occupation preoperatively, most of whom reported working a heavy-duty job $(\mathrm{n}=24,54.5 \%)$. Patients reporting heavy-duty occupational demands showed a significantly lower rate of RTW than their light-duty status counterparts $(33.5 \%$ vs $85.7 \%, P=.016)$. Patients working light-, moderate-, and heavy-duty status jobs required an average time to RTW of 2.6, 4.5, and 6.8. months, respectively (Table 4). Heavyintensity workers took significantly longer to RTW than light-intensity workers $(P=.044)$ but not moderate-intensity workers $(P=.243)$. Multivariate regression showed that revision surgical cases had increased odds of postoperative clinical symptoms including anterior biceps pain (odds ratio [OR], 1.69; $P=.034)$, a positive Yergason test result (OR, 1.44; $P=$ .047), and the consumption of opioid pain medications postoperatively (OR, 1.43; $P=.037$ ) (Table 5). With respect to factors impacting achievement of the MCID, a higher BMI was associated with decreased odds of achieving the MCID in the SF-12 PCS (OR, 0.964; $P=$ $.047)$ and VR-12 PCS (OR, 0.934; $P=.027$ ) outcome measures. Revision surgical cases also showed decreased odds of achieving the MCID in the SF-12 PCS (OR, 0.556, $P=.020$ ) and VR-12 PCS (OR, 0.533; $P=$ $.001)$. Patients with a history of psychiatric illness showed decreased odds of achieving the MCID in the CMS (OR, 0.464; $P=.002$ ) (Table 6). Within the follow-up period, no patients underwent subsequent revision surgery related to their operative extremity. However, 5 patients (10\%) experienced clinical tenodesis failure, as evidenced by the presence of a Popeye deformity on the operative side noted by both the patient and clinician. No significant differences in mean PROM scores were observed between patients in whom clinical failure developed and those without clinical failure at 6 months postoperatively (ASES score, $57.3 \pm 20.8$ vs $67.1 \pm 21.0[P=.332] ;$ CMS, $58.6 \pm 8.9$ vs $65.4 \pm 12.1[P=.234]$; SANE score, $68.3 \pm 9.6$ vs $67.8 \pm 21.0[P=.954]$; VAS score, $4.0 \pm 1.9$ vs $3.0 \pm$ $2.4[P=.338]$; SF-12 PCS, $37.9 \pm 9.7$ vs $39.9 \pm 9.1[P=$ $.640] ;$ SF-12 MCS, $51.1 \pm 10.5$ vs $50.2 \pm 11.1[P=$ $.877]$; VR-12 PCS, $39.9 \pm 7.9$ vs $42.1 \pm 9.2[P=.614]$; and VR-12 MCS, $54.9 \pm 7.8$ vs $53.2 \pm 12.0[P=.767])$. At final follow-up, patients who experienced clinical failure did have a significantly lower mean ASES score $(51.9 \pm 7.8$ vs $71.9 \pm 19.1, P=.027)$ than those who did not experience failure but had a similar SANE score $(71.3 \pm 20.0$ vs $73.4 \pm 23.6, P=.859)$.

\section{Discussion}

The major findings of our analysis showed significant improvements in postoperative shoulder strength and ROM, as well as improvements in multiple validated patient-reported outcome questionnaires, by 6 postoperative months after arthroscopic suprapectoral

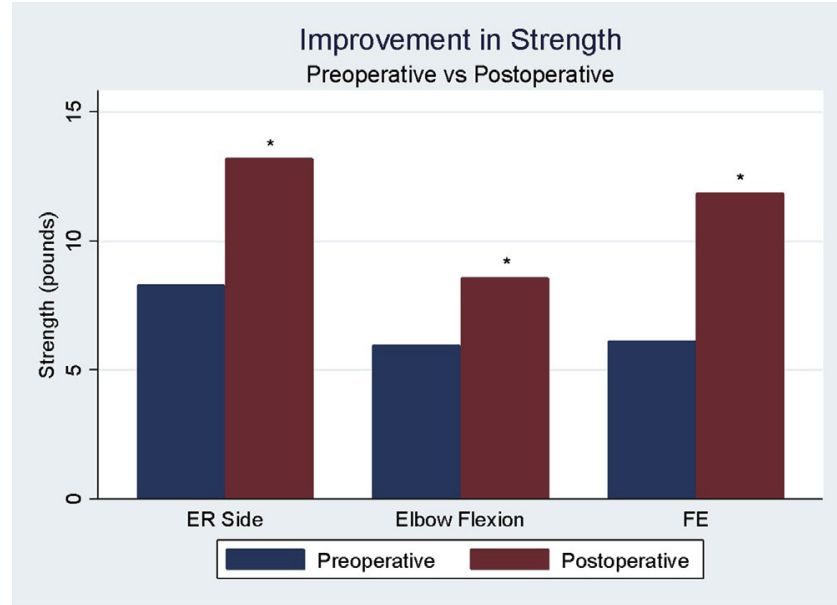

Fig 2. Postoperative improvement in shoulder and elbow strength testing. Mean preoperative and postoperative strength levels (in pounds) are shown for the described exercises. An asterisk indicates a statistically significant increase $(P<.05)$. (ER Side, shoulder external rotation with arm at side; FE, shoulder forward elevation.) 
Table 3. Improvement in Patient-Reported Outcome Measures

\begin{tabular}{lccc}
\hline \multicolumn{1}{c}{ PROM } & MCID & Preoperative & 6 mo \\
\hline ASES score & 11.6 & $37.2 \pm 17.9$ & $66.0 \pm 20.9^{* \dagger}$ \\
SANE score & 16.1 & $29.0 \pm 21.9$ & $67.9 \pm 19.8^{* \dagger}$ \\
VAS score & 1.5 & $6.1 \pm 2.4$ & $3.1 \pm 2.3^{* \dagger}$ \\
SF-12 MCS & 4.9 & $49.5 \pm 11.6$ & $50.4 \pm 11.0$ \\
SF-12 PCS & 4.7 & $33.1 \pm 6.1$ & $39.7 \pm 9.0^{* \dagger}$ \\
VR-12 MCS & 4.5 & $51.8 \pm 11.1$ & $53.4 \pm 11.6$ \\
VR-12 PCS & 4.7 & $34.9 \pm 6.7$ & $41.9 \pm 9.0^{* \dagger}$ \\
Constant-Murley score & 6.9 & $40.0 \pm 11.6$ & $64.6 \pm 11.9^{* \dagger}$ \\
\hline
\end{tabular}

NOTE. Data are presented as mean \pm standard deviation.

ASES, American Shoulder and Elbow Surgeons; MCID, minimal clinically important difference; MCS, mental component score; PCS, physical component score; PROM, patient-reported outcome measure; SANE, Single Assessment Numeric Evaluation; SF-12, 12-item Short Form; VAS, visual analog scale; VR-12, Veterans RAND 12-Item Health Survey.

*Achieved MCID.

${ }^{\dagger}$ Statistically significant improvement $(P<.05)$.

onlay biceps tenodesis using a single all-suture anchor. No significant differences in postoperative elbow strength, ROM, or the biceps apex distance were found when comparing operative versus contralateral extremities at 6 months. However, the presence of postoperative clinical cosmetic deformity was noted at a rate of $10 \%$, which was higher than expected. Most patients with preoperative occupations were able to RTW by an average of 6 months, with heavy-duty workers taking longer to return than light-duty workers. The results from our analysis of physical examination findings, objective strength and motion data, validated PROMs, and RTW supported our hypothesis by showing significant functional improvement and high rates of return to occupational activities within 6 months in our study population.

RTW outcomes after biceps tenodesis are deficient in the current literature, particularly regarding allarthroscopic techniques. In general, the available studies have suggested that patients can return to desired occupational and recreational activities at reasonably high rates postoperatively. Agarwalla et al. ${ }^{13}$ recently published a retrospective case series in which 60 of 76 patients $(78.9 \%)$ holding a preoperative occupation were able to return to the previous level of work intensity at an average of 5.4 months. It is important to note, however, that this cohort included both patients who underwent open tenodesis and those who underwent arthroscopic tenodesis. Similarly, Gombera et al. ${ }^{12}$ reported a series of 23 patients who underwent arthroscopic biceps tenodesis in which $78.3 \%$ fully returned to athletic activities by 18 months. Our cohort experienced comparable results, with $72.7 \%$ of patients with a preoperative occupation returning to work postoperatively at an average of 4.7 months. Notably, most of our working patient population (30 of 44 patients, $68.0 \%$ ) was being treated under Workers' Compensation claims. Although some authors have suggested that Workers' Compensation patients experience decreased outcomes compared with the general population after biceps tenodesis and other shoulder surgical procedures, our overall high rate of RTW in a study population largely consisting of workrelated injuries showed this not to be the case. ${ }^{26-29}$ Nevertheless, heavy-duty workers did, indeed, return to their occupations at a significantly lower rate and took substantially longer to return compared with lightduty workers. Our findings suggest that although arthroscopic suprapectoral onlay single-anchor biceps tenodesis in conjunction with other common shoulder

Table 4. Total RTW and RTW by Occupation Intensity

\begin{tabular}{|c|c|c|c|c|}
\hline & \multicolumn{4}{|c|}{ Arthroscopic Suprapectoral Onlay Bicep Tenodesis } \\
\hline & Preoperative Employment, $\mathrm{n}$ & Postoperative Employment, $\mathrm{n}$ & RTW Rate, \% & Time to RTW, Mean \pm SD, mo \\
\hline \multicolumn{5}{|l|}{ Duty status } \\
\hline Light & 7 & 6 & 85.7 & $2.6 \pm 2.0$ \\
\hline Heavy & 24 & 8 & $33.3 *$ & $6.8^{\dagger} \pm 4.2$ \\
\hline Total & 44 & $32^{\ddagger}$ & 72.7 & $4.7 \pm 2.9$ \\
\hline
\end{tabular}


Table 5. Logistic Regression of Variables Associated With Postoperative Outcomes

\begin{tabular}{|c|c|c|c|}
\hline & \multicolumn{2}{|c|}{$P$ Value } & \multirow[b]{2}{*}{ Or $(95 \% \mathrm{CI})$} \\
\hline & UR & MR & \\
\hline \multicolumn{4}{|l|}{ Abnormal } \\
\hline Sex & .101 & .248 & $1.116(0.926-1.346)$ \\
\hline Current smoker & .078 & .182 & $1.166(0.930-1.461)$ \\
\hline \multicolumn{4}{|l|}{$\begin{array}{l}\text { Postoperative bicipital } \\
\text { groove pain }\end{array}$} \\
\hline BMI & .051 & .061 & $1.021(-0.001$ to 0.043$)$ \\
\hline Revision & $.038^{*}$ & $.034^{\star}$ & $1.691(1.041-2.747)^{*}$ \\
\hline \multicolumn{4}{|l|}{ Positive O'Brien test result } \\
\hline BMI & .053 & .087 & $1.021(0.997-1.045)$ \\
\hline WC & .133 & .564 & $1.091(0.811-1.469)$ \\
\hline Hypercholesterolemia & .065 & .077 & $1.450(0.959-2.191)$ \\
\hline \multicolumn{4}{|l|}{$\begin{array}{l}\text { Positive Yergason test } \\
\text { result }\end{array}$} \\
\hline Current smoker & .073 & .279 & $1.148(0.894-1.473)$ \\
\hline Revision & $.144^{*}$ & $.047 *$ & $1.447(1.006-2.083)^{*}$ \\
\hline $\mathrm{RC}$ debridement & .098 & .124 & $0.822(0.640-1.055)$ \\
\hline Labral repair & .180 & .550 & $2.04(0.985-4.261)$ \\
\hline \multicolumn{4}{|l|}{ Pain medications } \\
\hline BMI & .041 & .074 & $1.038(0.996-1.091)$ \\
\hline Revision & .193 & .667 & $1.132(0.643-1.994)$ \\
\hline $\begin{array}{l}\text { Preoperative bicipital } \\
\text { groove pain }\end{array}$ & .115 & .213 & $1.297(0.861-1.953)$ \\
\hline \multicolumn{4}{|l|}{ Opioid pain mdications } \\
\hline Sex & .054 & .073 & $1.185(0.985-1.426)$ \\
\hline WC & .134 & .341 & $1.102(0.902-1.347)$ \\
\hline HTN & .130 & .053 & $0.805(0.646-1.003)$ \\
\hline Revision & $.031^{*}$ & $.037 *$ & $1.433(1.022-2.009)^{*}$ \\
\hline \multicolumn{4}{|l|}{ RTW } \\
\hline RCR with SAD & .136 & .272 & $0.852(0.640-1.134)$ \\
\hline SAD & .199 & .426 & $0.818(0.501-1.339)$ \\
\hline \multicolumn{4}{|l|}{$\begin{array}{l}\text { RTW at same or higher } \\
\text { intensity }\end{array}$} \\
\hline Past smoker & .082 & .164 & $0.805(0.594-1.093)$ \\
\hline Psychiatric comorbidity & .167 & .654 & $0.802(0.305-2.105)$ \\
\hline Revision & .045 & .094 & $0.643(0.383-1.079)$ \\
\hline SAD & .045 & .416 & $1.34(0.660-2.727)$ \\
\hline
\end{tabular}

BMI, body mass index; CI, confidence interval; HTN, hypertension; $\mathrm{MR}$, multivariate regression; OR, odds ratio; RC, rotator cuff; RCR, rotator cuff repair; RTW, return to work; SAD, subacromial decompression; UR, univariate regression; WC, Workers' Compensation.

*Statistically significant findings $(P<.05)$.

procedures may help provide overall reliable results for patients looking to return to occupational duties, the postoperative return among individuals with more intense physical demands may be prolonged and less predictable. It would be beneficial for surgeons to take this into account when counseling heavy-duty laborers preoperatively because fulfillment of preoperative expectations has been significantly linked with postoperative patient satisfaction. ${ }^{30-34}$

In recent systematic reviews by Abraham et al. ${ }^{35}$ and Hurley et al., ${ }^{36}$ the authors showed that arthroscopic biceps tenodesis could lead to significant improvements in validated outcome scores (ASES, Simple Shoulder Test, VAS, and Disabilities of the Arm, Shoulder and
Hand scores) and clinical ROM postoperatively, with results comparable to those of open techniques. Our analysis produced similar results, with significant postoperative improvements seen in clinical strength, as well as nearly all ROM parameters and PROM scores. Prior investigations have shown that the timing of maximum medical improvement after isolated biceps tenodesis occurs at 6 months postoperatively and that after arthroscopic rotator cuff repair occurs at 12 months. ${ }^{37,38}$ In our study cohort, arthroscopic rotator cuff repair was the most frequently performed concomitant procedure with biceps tenodesis. According to the available evidence, it is reasonable to conclude that clinically significant improvements in PROMs, ROM, and strength within our patient population were likely captured during the current study period-and are not expected to occur beyond this. When evaluating outcome score improvements in detail, the MCID is a figure that represents the smallest quantifiable improvement for a given PROM considered worthwhile by a patient. ${ }^{39,40}$ In our study population, we found that patients with increased BMI, those with psychiatric comorbidities, and those undergoing revision procedures were less likely to achieve the MCID threshold for multiple PROMs. These results support the assertion that our described surgical technique can reliably lead to improved symptoms and functionality perceived relatively quickly by patients in the short-term postoperative period. It is important to note, however, that patients with morbid obesity, as well as those with psychiatric histories and those scheduled for revision surgery, may not detect symptomatic improvement as quickly on the basis of our findings. These results would have relevant implications for clinicians looking to counsel patients with similar demographic characteristics regarding expectations for postoperative symptomatic improvement.

The most commonly described complications after arthroscopic biceps tenodesis include persistent bicipital groove pain $(5.7 \%-34.8 \%)$, stiffness $(9.4 \%-17.9 \%)$, and tenodesis failure or Popeye deformity $(2.9 \%$ $15.2 \%) .{ }^{36,41-46}$ In a retrospective analysis of 33 patients who underwent arthroscopic biceps tenodesis with concomitant rotator cuff repair, Jeong et al. ${ }^{42}$ reported the highest described rate of postoperative Popeye deformity in the literature of $15.6 \%$. This was greater than the rate in their comparative open biceps tenodesis cohort of 39 patients $(5.2 \%)$, but this finding did not reach statistical significance. ${ }^{42}$ Other investigators have reported much lower incidences of persistent cosmetic deformity after arthroscopic tenodesis $(<5 \%)$, with some reporting no instances of cosmetic deformity postoperatively. ${ }^{12,43,46}$ Although the average biceps apex distance between the operative and nonoperative sides did not differ in our analysis, a noticeable Popeye deformity developed postoperatively in 5 patients 
Tabl 6. Logistic Regression of Variables Associated With MCID Achievement

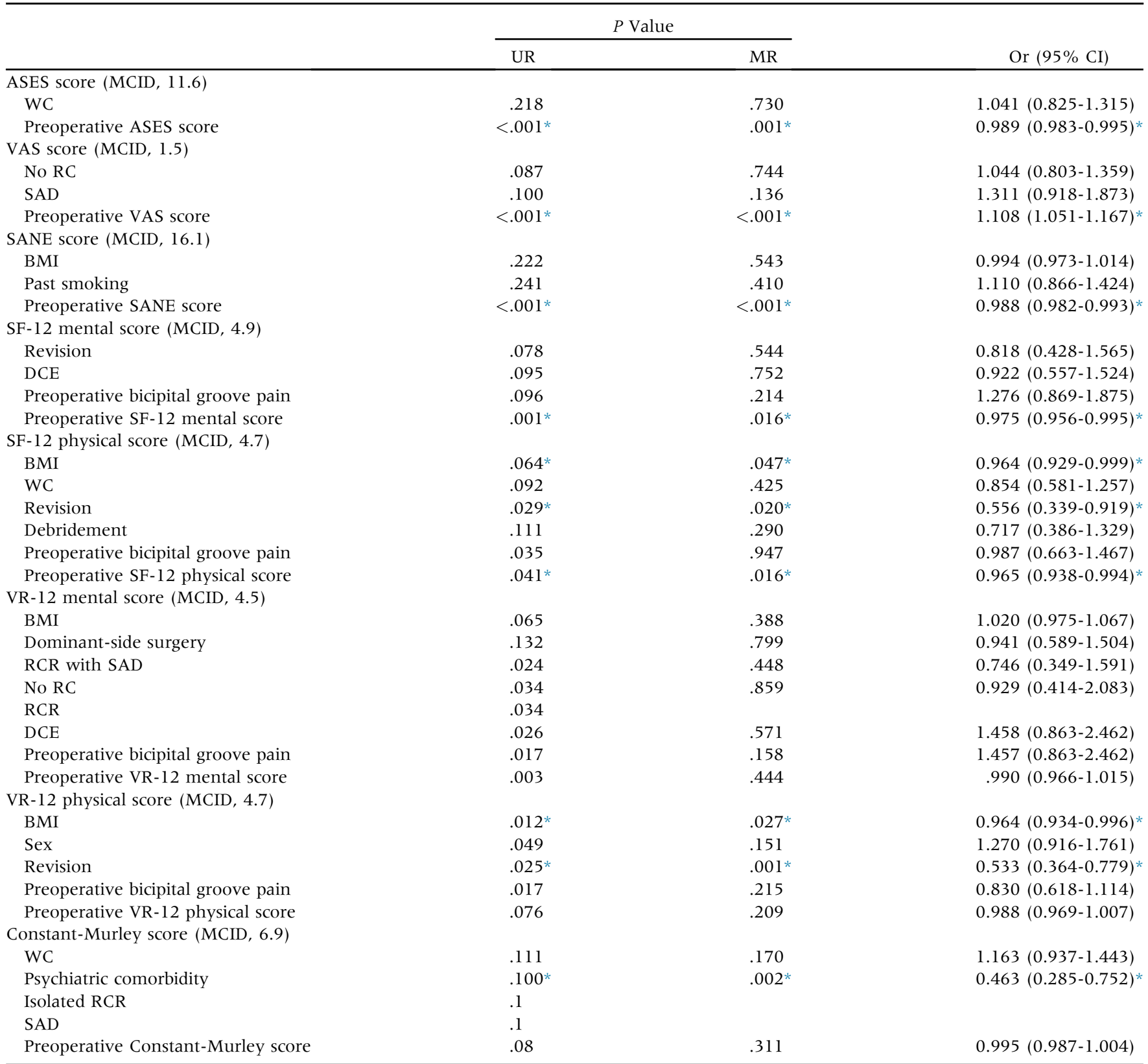

ASES, American Shoulder and Elbow Surgeons; BMI, body mass index; CI, confidence interval; DCE, distal clavicle excision; MCID, minimal clinically important difference; MR, multivariate regression; OR, odds ratio; RC, rotator cuff; RCR, rotator cuff repair; SAD, subacromial decompression; SANE, Single Assessment Numeric Evaluation; SF-12, 12-item Short Form; UR, univariate regression; VAS, visual analog scale for pain; VR-12, Veterans RAND 12-Item Health Survey; WC, Workers' Compensation.

*Statistically significant findings $(P<.05)$.

$(10.0 \%)$. These findings are clinically significant considering that many authors advocate the performance of tenodesis versus tenotomy in active or working populations, such as our population, owing to the decreased reported risk of cosmetic deformity. ${ }^{3,47-49}$ In the 5 patients in whom a Popeye deformity developed, the mean ASES score was significantly lower than that in the rest of the study population at final follow-up. The mean SANE scores showed no significant differences. Prior evidence has shown the ASES and SANE scores to possess strong statistical correlations after shoulder surgery. ${ }^{50-52}$ This was not the case in our analysis. These findings may suggest that patients experiencing postoperative cosmetic deformity may also perceive some functional deficit. However, these findings should be interpreted with caution because this comparison is likely underpowered given the small sample size of failures and insufficient to draw 
strong clinical conclusions. One potential reason for the development of clinical failure postoperatively could be inferior stability of the repair owing to the type of implant chosen. Although biomechanical studies have shown similar fixation strengths among suture anchor, interference screw, and other arthroscopic tenodesis constructs, no clinical consensus exists regarding which is most reliable. ${ }^{46,53,54}$ Perhaps other options for suture anchor fixation-or the use of additional anchors to fortify the repair-may lead to improved tenodesis fixation and decreased rates of deformity. In addition, an onlay technique may result in decreased tendonbone healing in comparison to tunnel-based techniques, contributing to failure. Investigating the clinical impact of various arthroscopic fixation constructs would be an interesting area of future study not currently addressed in the literature.

Given the relatively recent introduction of arthroscopic suprapectoral biceps tenodesis techniques, clinical investigations are still in the early stages. Although longer-term follow-up may have been ideal, our study design allowed us to detect clinically significant improvements in nearly all analyzed parameters (PROMs, ROM, and strength), as well as to capture when most patients returned to work. Recent investigations have shown increasing volumes of concomitant procedures being performed with both open and arthroscopic biceps tenodeses that parallel the expanding volumes of tenodeses overall. ${ }^{5}$ Theoretically, an assessment of patients undergoing an isolated biceps tenodesis procedure would be preferable to evaluate the results of this particular procedure. However, assembling a patient population comprising isolated biceps tenodesis procedures using this technique large enough for adequate study would not have been practical or an accurate reflection of the current clinical population undergoing biceps tenodesis. This study's description of functional and RTW outcomes can provide a useful basis of comparison for future prospective, randomized, controlled trials investigating arthroscopic tenodesis techniques. The consistent use of validated PROMs and previously described indices of clinical progress (i.e., biceps apex distance and biceps-specific testing) allows for facile comparison of findings to past and future investigations. The results of our analysis provide surgeons with clinically relevant information for preoperative counseling when attempting to establish evidence-based realistic expectations for their patients' postoperative course.

\section{Limitations}

Our study is not without limitations. The retrospective nature and lack of a control group or comparison to other techniques inherently limit the level of evidence our analysis can provide. Furthermore, the short-term period of follow-up restricts the scope of our findings and our ability to assess potential long-term complications that may not have become apparent by the time of final follow-up. We also recognize that the presence of concomitant procedures likely impacted patient clinical outcomes and RTW. Finally, because the biceps muscle is the main supinator of the upper extremity, it would have been clinically relevant to collect supination strength data or determine the presence of cramping with repetitive supination or twisting motions. Unfortunately, the dynamometer equipment used in this study was not capable of obtaining grip strength measurements to assess supination and pronation. Thus, elbow flexion was used as an indicator of biceps strength in a consistent fashion.

\section{Conclusions}

Arthroscopic suprapectoral onlay biceps tenodesis with a single all-suture anchor can provide overall excellent clinical outcomes regarding strength, motion, and validated patient-reported outcome questionnaires. Return to occupational activities may be less predictable and more prolonged for heavy laborers. A small number of patients may experience cosmetic deformity postoperatively.

\section{References}

1. MacDonald P, Verhulst F, McRae S, et al. Biceps tenodesis versus tenotomy in the treatment of lesions of the long head of the biceps tendon in patients undergoing arthroscopic shoulder surgery: A prospective doubleblinded randomized controlled trial. Am J Sports Med 2020;48:1439-1449.

2. Checchia SL, Doneux PS, Miyazaki AN, et al. Biceps tenodesis associated with arthroscopic repair of rotator cuff tears. J Shoulder Elbow Surg 2005;14:138-144.

3. Galdi B, Southren DL, Brabston EW, et al. Patients have strong preferences and perceptions for biceps tenotomy versus tenodesis. Arthroscopy 2016;32:2444-2450.

4. Vellios EE, Nazemi AK, Yeranosian MG, et al. Demographic trends in arthroscopic and open biceps tenodesis across the United States. J Shoulder Elbow Surg 2015;24:e279-e285.

5. Werner BC, Brockmeier SF, Gwathmey FW. Trends in long head biceps tenodesis. Am J Sports Med 2015;43: 570-578.

6. Erickson BJ, Jain A, Cvetanovich GL, et al. Biceps tenodesis: An evolution of treatment. Am J Orthop (Belle Mead NJ) 2017;46:E219-E223.

7. Hong CK, Hsu KL, Kuan FC, Lin CL, Yeh ML, Su WR. Biomechanical evaluation of a transtendinous all-suture anchor technique versus interference screw technique for suprapectoral biceps tenodesis in a cadaveric model. Arthroscopy 2018;34:1755-1761.

8. Diaz M, Shi BY, Baker MC, Binkley MT, Belkoff SM, Srikumaran U. Open biceps tenodesis: A biomechanical comparison of 6 fixation techniques. Orthopedics 2020;43: el02-el08. 
9. Frank RM, Bernardoni ED, Veera SS, et al. Biomechanical analysis of all-suture suture anchor fixation compared with conventional suture anchors and interference screws for biceps tenodesis. Arthroscopy 2019;35:1760-1768.

10. Chiang FL, Hong CK, Chang CH, Lin CL, Jou IM, Su WR. Biomechanical comparison of all-suture anchor fixation and interference screw technique for subpectoral biceps tenodesis. Arthroscopy 2016;32:1247-1252.

11. Mazzocca AD, Bicos J, Santangelo S, Romeo AA, Arciero RA. The biomechanical evaluation of four fixation techniques for proximal biceps tenodesis. Arthroscopy 2005:21:1296-1306.

12. Gombera MM, Kahlenberg CA, Nair R, Saltzman MD, Terry MA. All-arthroscopic suprapectoral versus open subpectoral tenodesis of the long head of the biceps brachii. Am J Sports Med 2015;43:1077-1083.

13. Agarwalla A, Gowd AK, Liu JN, et al. Predictive factors and the duration to pre-injury work status following biceps tenodesis. Arthroscopy 2019;35:1026-1033.

14. Thigpen CA, Shanley E, Momaya AM, et al. Validity and responsiveness of the single alpha-numeric evaluation for shoulder patients. Am J Sports Med 2018;46:3480-3485.

15. Michener LA, McClure PW, Sennett BJ. American Shoulder and Elbow Surgeons Standardized Shoulder Assessment Form, patient self-report section: Reliability, validity, and responsiveness. J Shoulder Elbow Surg 2002;1 1:587-594.

16. Rocourt MH, Radlinger L, Kalberer F, et al. Evaluation of intratester and intertester reliability of the ConstantMurley shoulder assessment. J Shoulder Elbow Surg 2008; 17:364-369.

17. Constant C, Murley A. A clinical method of functional assessment of the shoulder. Clin Orthop Relat Res 1987: 160-164.

18. Tashjian RZ, Deloach J, Porucznik CA, Powell AP. Minimal clinically important differences (MCID) and patient acceptable symptomatic state (PASS) for visual analog scales (VAS) measuring pain in patients treated for rotator cuff disease. J Shoulder Elbow Surg 2009;18: 927-932.

19. Kazis LE, Miller DR, Skinner KM, et al. Applications of methodologies of the Veterans Health Study in the VA healthcare system: Conclusions and summary. J Ambul Care Manage 2006;29:182-188.

20. Ware JE Jr, Kosinski M, Keller SD. A 12-Item Short-Form Health Survey: Construction of scales and preliminary tests of reliability and validity. Med Care 1996:220-233.

21. Mazzocca AD, Cote MP, Arciero CL, Romeo AA, Arciero RA. Clinical outcomes after subpectoral biceps tenodesis with an interference screw. Am J Sports Med 2008;36:1922-1929.

22. U.S. Department of Labor Office of Administrative Law Judges Law Library. Dictionary of occupational titles (fourth edition, revised 1991). Washington, DC: U.S. Department of Labor, 1991.

23. Beletsky A, Cancienne JM, Leroux T, Manderle BJ, Chahla J, Verma NN. Arthroscopic tenodesis of the long head biceps tendon using a double lasso-loop suture anchor configuration. Arthrosc Tech 2019;8:e1137-el143.

24. Harris JD, Brand JC, Cote MP, Faucett SC, Dhawan A. Research pearls: The significance of statistics and perils of pooling. Part 1: Clinical versus statistical significance. Arthroscopy 2017;33:1102-1112.

25. Katz NP, Paillard FC, Ekman E. Determining the clinical importance of treatment benefits for interventions for painful orthopedic conditions. J Orthop Surg Res 2015;10:24.

26. Cvetanovich GL, Savin DD, Frank RM, et al. Inferior outcomes and higher complication rates after shoulder arthroplasty in workers' compensation patients. J Shoulder Elbow Surg 2019;28:875-881.

27. Lu Y, Agarwalla A, Patel BH, et al. Influence of workers' compensation status on postoperative outcomes in patients following biceps tenodesis: A matched-pair cohort analysis. J Shoulder Elbow Surg 2020;29:2530-2537.

28. Koljonen P, Chong C, Yip D. Difference in outcome of shoulder surgery between workers' compensation and nonworkers' compensation populations. Int Orthop 2009;33:315-320.

29. Henn RF III, Tashjian RZ, Kang L, Green A. Patients with workers' compensation claims have worse outcomes after rotator cuff repair. J Bone Joint Surg Am 2008;90: 2105-2113.

30. Husain A, Lee GC. Establishing realistic patient expectations following total knee arthroplasty. J Am Acad Orthop Surg 2015;23:707-713.

31. Filbay SR, Judge A, Delmestri A, Arden NK. Evaluating patients' expectations from a novel patient-centered perspective predicts knee arthroplasty outcome. J Arthroplasty 2018;33:2146-2152.e2144.

32. Cole BJ, Cotter EJ, Wang KC, Davey A. Patient understanding, expectations, and satisfaction regarding rotator cuff injuries and surgical management. Arthroscopy 2017;33:1603-1606.

33. Noble PC, Conditt MA, Cook KF, Mathis KB. The John Insall Award: Patient expectations affect satisfaction with total knee arthroplasty. Clin Orthop Relat Res 2006;452: 35-43.

34. Culliton SE, Bryant DM, Overend TJ, MacDonald SJ, Chesworth BM. The relationship between expectations and satisfaction in patients undergoing primary total knee arthroplasty. J Arthroplasty 2012;27:490-492.

35. Abraham VT, Tan BH, Kumar VP. Systematic review of biceps tenodesis: Arthroscopic versus open. Arthroscopy 2016;32:365-371.

36. Hurley DJ, Hurley ET, Pauzenberger L, Lim Fat D, Mullett H. Open compared with arthroscopic biceps tenodesis: A systematic review. JBJS Rev 2019;7:e4.

37. Puzzitiello RN, Gowd AK, Liu JN, Agarwalla A, Verma NN, Forsythe B. Establishing minimal clinically important difference, substantial clinical benefit, and patient acceptable symptomatic state after biceps tenodesis. J Shoulder Elbow Surg 2019;28:639-647.

38. Zuke WA, Leroux TS, Gregory BP, et al. Establishing maximal medical improvement after arthroscopic rotator cuff repair. Am J Sports Med 2018;46:1000-1007.

39. Tashjian RZ, Hung M, Keener JD, et al. Determining the minimal clinically important difference for the American Shoulder and Elbow Surgeons score, Simple Shoulder Test, and visual analog scale (VAS) measuring pain after shoulder arthroplasty. J Shoulder Elbow Surg 2017;26: 144-148. 
40. Copay AG, Subach BR, Glassman SD, Polly DW Jr, Schuler TC. Understanding the minimum clinically important difference: A review of concepts and methods. Spine J 2007;7:541-546.

41. Yi Y, Lee JM, Kwon SH, Kim JW. Arthroscopic proximal versus open subpectoral biceps tenodesis with arthroscopic repair of small- or medium-sized rotator cuff tears. Knee Surg Sports Traumatol Arthrosc 2016;24:3772-3778.

42. Jeong HY, Kim JY, Cho NS, Rhee YG. Biceps lesion associated with rotator cuff tears: Open subpectoral and arthroscopic intracuff tenodesis. Orthop J Sports Med 2016;4:2325967116645311.

43. Duchman KR, DeMik DE, Uribe B, Wolf BR, Bollier M. Open versus arthroscopic biceps tenodesis: A comparison of functional outcomes. Iowa Orthop J 2016;36:79-87.

44. Brady PC, Narbona P, Adams CR, et al. Arthroscopic proximal biceps tenodesis at the articular margin: Evaluation of outcomes, complications, and revision rate. Arthroscopy 2015;31:470-476.

45. McCrum CL, Alluri RK, Batech M, Mirzayan R. Complications of biceps tenodesis based on location, fixation, and indication: A review of 1526 shoulders. J Shoulder Elbow Surg 2019;28:461-469.

46. Deng ZJ, Yin C, Cusano J, et al. Outcomes and complications after primary arthroscopic suprapectoral versus open subpectoral biceps tenodesis for superior labral anterior-posterior tears or biceps abnormalities: A systematic review and meta-analysis. Orthop J Sports Med 2020;8:2325967120945322.

47. Belk JW, Kraeutler MJ, Houck DA, Chrisman AN, Scillia AJ, McCarty EC. Biceps tenodesis versus tenotomy: A systematic review and meta-analysis of level I randomized controlled trials. J Shoulder Elbow Surg 2021;30:951-960.
48. Hsu AR, Ghodadra NS, Provencher MT, Lewis PB, Bach BR. Biceps tenotomy versus tenodesis: A review of clinical outcomes and biomechanical results. J Shoulder Elbow Surg 2011;20:326-332.

49. Slenker NR, Lawson K, Ciccotti MG, Dodson CC, Cohen SB. Biceps tenotomy versus tenodesis: Clinical outcomes. Arthroscopy 2012;28:576-582.

50. Gowd AK, Charles MD, Liu JN, et al. Single Assessment Numeric Evaluation (SANE) is a reliable metric to measure clinically significant improvements following shoulder arthroplasty. J Shoulder Elbow Surg 2019;28: 2238-2246.

51. Cunningham G, Lädermann A, Denard PJ, Kherad O, Burkhart SS. Correlation between American Shoulder and Elbow Surgeons and Single Assessment Numerical Evaluation score after rotator cuff or SLAP repair. Arthroscopy 2015;31:1688-1692.

52. Retzky JS, Baker M, Hannan CV, Srikumaran U. Single Assessment Numeric Evaluation scores correlate positively with American Shoulder and Elbow Surgeons scores postoperatively in patients undergoing rotator cuff repair. J Shoulder Elbow Surg 2020;29:146-149.

53. Poberaj B, Marjanovič B, Zupančič M, et al. Biomechanical comparison of the three techniques for arthroscopic suprapectoral biceps tenodesis: Implantfree intraosseous tendon fixation with Cobra Guide, interference screw and suture anchor. Musculoskelet Surg 2020; 104:49-57.

54. Kany J, Guinand R, Croutzet P, Amaravathi R, Sekaran P. Biceps tenodesis (long head): Arthroscopic keyhole technique versus arthroscopic interference screw: A prospective comparative clinical and radiographic marker study. Eur J Orthop Surg Traumatol 2016;26:77-84. 
Appendix Table 1. Categorization of Occupational Demands

Duty Intensity

Light

Moderate

Heavy
Definition

Exerting up to 20 pounds of force occasionally, and/or up to 10 pounds of force frequently, and/or a negligible amount of force constantly (constantly: activity or condition exists $2 / 3$ or more of the time) to move objects. Physical demand requirements are in excess of those for sedentary work. Even though the weight lifted may be only a negligible amount, a job should be rated light work: (1) when it requires walking or standing to a significant degree; or (2) when it requires sitting most of the time but entails pushing and/or pulling of arm or leg controls; and/or (3) when the job requires working at a production rate pace entailing the constant pushing and/or pulling of materials even though the weight of those materials is negligible. NOTE: The constant stress and strain of maintaining a production rate pace, especially in an industrial setting, can be and is physically demanding of a worker even though the amount of force exerted is negligible.

Exerting 20 to 50 pounds of force occasionally, and/or 10 to 25 pounds of force frequently, and/or greater than negligible up to 10 pounds of force constantly to move objects. Physical demand requirements are in excess of those for light work.

Exerting 50 to 100 pounds of force occasionally, and/or 25 to 50 pounds of force frequently, and/or 10 to 20 pounds of force constantly to move objects. Physical demand requirements are in excess of those for medium work.

NOTE. The source of information is U.S. Department of Labor Office of Administrative Law Judges Law Library. Dictionary of occupational titles (fourth edition, revised 1991). Washington, DC: U.S. Department of Labor, 1991. 